\title{
Extraction and Solubility Modeling of Anthocyanins Rich Extract from Hibiscus sabdariffa $L$. using Supercritical Carbon Dioxide
}

\author{
Zuhaili Idham ${ }^{a, b, *}$, Nicky Rahmana Putraa , Hasmida Nasira, Lee Nian-Yianª, \\ Nor Faadila Mohd Idrus ${ }^{a, b}$, Mohd Azizi Che Yunusa,b \\ a Centre of Lipids Engineering and Applied Research (CLEAR), Ibnu Sina Institute \\ for Scientific and Industrial Research, Universiti Teknologi Malaysia, 81310, UTM \\ Johor Bahru, Malaysia; ${ }^{b}$ School of Chemical and Energy Engineering, Faculty of \\ Engineering, Universiti Teknologi Malaysia, 81310, UTM Johor Bahru, Malaysia
}

Abstract This study aimed to evaluate the extraction yield, and anthocyanins content of Hibiscus sabdariffa $L$. calyces extract using different temperatures $(T)$ at $50-70^{\circ} \mathrm{C}$, pressure $(P)$ at $8-12 \mathrm{MPa}$, and modifier ratio at $5-10 \%$. This work used a supercritical carbon dioxide (SC$\mathrm{CO} 2)$ extraction with ethanol and water as a modifier. The solubility of the extract was then measured before correlating using Chrastil, del Valle \& Aguilera (dVA), and Adachi-Lu (A-L) models. This study revealed that a low $\mathrm{T}$ and increase in $\mathrm{P}$ at a constant modifier ratio would boost the anthocyanins content, contradicted with the extraction of total yield value, which is higher when increase T and low P. Meanwhile, analyzed results show that the solubility of Hibiscus sabdariffa calyces' extracts has successfully fitted the Chrastil's model with AARD of $27.72 \%$ as compared with dVA $(35.42 \%)$ and A-L models $(50.23 \%)$.

Keywords: Hibiscus sabdariffa, Anthocyanins, Supercritical carbon dioxide, solubility, modeling,

*For correspondence: zuhaili@cheme.utm.my Received: 19 Nov 2020 Accepted: 19 Feb 2021

(C) Copyright Idham et al. This article is distributed under the terms of the Creative Commons Attribution License, which permits unrestricted use and redistribution provided that the original author and source are credited.

\section{Introduction}

Hibiscus sabdariffa L. (H. sabdariffa) or Roselle is a tropical annual herb plant that belongs to Malvaceae family ${ }^{1}$. The calyces are rich in anthocyanins, the red color pigment. It is abundantly found in Malaysia and has become one of the most important commercial crops. The fleshy red calyces' components in $H$. sabdariffa are the most frequently used to make wine, syrup, or ice cream. Meanwhile, the dry calyces are limitedly used for tea and infusion drinks ${ }^{2}$. The major components found in $H$. sabdariffa anthocyanins are delphinidin-3-sambubioside, cyanidin-3-sambubioside, and cyanidin-3-glucoside ${ }^{3}$. Anthocyanins are flavonoid pigments soluble in water and have been extensively used in food ingredients such as industrial colorants, supplements, and health-promoting food. Due to its antiinflammatory, antioxidant, and anti-carcinogenic properties, anthocyanins as food colorants could improve the overall appearance and have beneficial health effects on several chronic diseases ${ }^{3-5}$.

These positive effects of anthocyanins have initiated extensive research on their benefits, applications, and extraction techniques. It is acknowledged that acidified solvent extraction is the most common method of extracting anthocyanins using polar solvents like water, ethanol, and methanol ${ }^{6-8}$. Pragalyaashree et al. ${ }^{6}$ discovered that acidified ethanol with acid hydrochloric gave the highest anthocyanin extract of $3.35 \mathrm{mg} / \mathrm{g}$ dry $H$. sabdariffa calyces.

Due to the requirements in industries (e.g., environmental, public health, and energy factors), the use of 
greener extraction methods in the food and chemical sectors has gained considerable attention. Supercritical carbon dioxide $\left(\mathrm{SC}-\mathrm{CO}_{2}\right)$ extraction with polar solvent as modifier has been introduced for anthocyanins extraction in several plants such as purple corn cob, Crocus sativus petals, chokeberry, haskap berry pulp, jucara ${ }^{9-13}$. Small amounts of polar modifiers, like water and ethanol, were added to enhance $\mathrm{SC}-\mathrm{CO}_{2}$ solvent strength, an affinity for poorly soluble solutes, and, eventually, extraction yield 14. The presence of water could produce in situ carbonic acids and provide low pH conditions to increase cell membrane permeability, resulting in cell disruption and could release the anthocyanins from calyx's vacuole ${ }^{10-13}$. It has been shown that $\mathrm{SC}-\mathrm{CO}_{2}$ extraction methods seem to have a high recovery yield for bioactive compounds compared to conventional methods by manipulation of $\mathrm{SC}-\mathrm{CO}_{2}$ conditions. Other than that, $\mathrm{SC}-\mathrm{CO}_{2}$ can be more advantageous than other advanced extraction methods in terms of purity, antioxidant activity, antibacterial activity, and thermal stability of the extracts obtained ${ }^{15}$.

Pimentel-Moral et al., ${ }^{16}$ applied $\mathrm{SC}-\mathrm{CO}_{2}$ extraction with ethanol as a modifier to recover phenolic and organic acids in $\mathrm{H}$. sabdariffa calyces. Our previous study optimized the $\mathrm{SC}-\mathrm{CO}_{2}$ conditions on $\mathrm{H}$. sabdariffa calyces extract yield within the experimental range of parameters in this work ${ }^{17}$. However, this work was further performed to compare and evaluate the effect of temperature, pressure, and cosolvent ratios between total extraction yield and anthocyanins compound.

Solubility refers to the maximum amount of extracted solute at a saturation equilibrium ${ }^{18}$. Solubility measurement can be conducted by experimental or modeling. Semi-empirical models were chosen to determine the solubility behavior, thus supporting the design and identification of $\mathrm{SC}-\mathrm{CO}_{2}$ operating conditions. Chrastil developed the most common semi-empirical models to analyze the solubility of the solution ${ }^{19}$. At the same time, Adachi-Lu (A-L) ${ }^{20}$ and del Valle and Aguilera (dVA) ${ }^{21}$ were modified with a few parameters into the initial equations. As far as we know, only Lukmanto et al. ${ }^{22}$ has been focusing on the solubility data of $H$. sabdariffa, specifically only on phenolic compounds using the extraction of $\mathrm{SC}-\mathrm{CO}_{2}$ with acetone modifier.

Therefore, the purposes of this study were to assess the effect of the $\mathrm{SC}-\mathrm{CO}_{2}$ extraction temperature, pressure, and modifier ratio on total extraction yield and cyanidin 3- glucoside as one of the anthocyanins compounds in $H$. sabdariffa calyces and to correlate the extraction solubility data with three different semi-empirical models by Chrastil, A-L, and dVA, respectively. Three different conditions: temperature $\left(50-70{ }^{\circ} \mathrm{C}\right)$, pressure $(8-12 \mathrm{MPa})$, and modifier ratio $(5 \%-10 \%)$ of $6 \mathrm{~mL} / \mathrm{min}$ of solvent flow rate were used in this study implementing $\mathrm{SC}-\mathrm{CO}_{2}$ extraction technique.

\section{Materials and methods}

\section{Materials}

Dry $H$. sabdariffa calyces from the UMKL variety were purchased from Ekomekar Resources, Terengganu, Malaysia. The dried calyces were ground and mesh sieved to achieve a range of sizes of $200-355 \mu \mathrm{m}$. A screw-capped glass bottle was used to keep the sample, protect it from light, and placed at $-18^{\circ} \mathrm{C}$ for further use.

\section{Chemicals}

Carbon dioxide (99.9\%) was purchased from KRAS Instrument Sdn Bhd (Malaysia), while the absolute ethanol (99.89\%) and acetonitrile were bought from Sigma-Aldrich (Singapore). On the other hand, kuromanin chloride (cyanidin 3-glucoside) was obtained from Extrasynthese (German).

\section{$\mathrm{SC}-\mathrm{CO}_{2}$ extraction}

As shown in Figure 1, $\mathrm{H}$. sabdariffa calyces were extracted using a lab-scale of $\mathrm{SC}-\mathrm{CO}_{2}$ extractor, assisted by ethanol: water (75:25 v/v) as a modifier. Samples were taken out of the freezer and stored at room temperature for thawing purposes. $1500 \mathrm{mg}$ of dry $\mathrm{H}$. sabdariffa powder was placed into an extraction vessel before being tightly sealed. The chiller temperature was set at $6{ }^{\circ} \mathrm{C}$, while the heater on the backpressure regulator (Jasco BP 2080 Plus Automated BPR) was set at $50{ }^{\circ} \mathrm{C}$. Next, liquid $\mathrm{CO}_{2}$ was pumped by a $\mathrm{CO}_{2}$ pump (Lab Alliance, Series II) equipped with an automated flow rate meter. 
Modifier was also pumped using a $10 \mathrm{~mL}$ Series II pump (Scientific Systems, Inc., USA) with three modifier ratios of $5,7.5$, and $10 \%$ from a total solvent flow rate of $6 \mathrm{~mL} / \mathrm{min}$ as determined in our preliminary study ${ }^{23}$. The desired temperature of $50,60,70{ }^{\circ} \mathrm{C}$ and pressure of $8,10,12 \mathrm{MPa}$ were set. Because of the cost-effective approach to developing high-quality plant extracts, a low-pressure $\mathrm{CO}_{2}$ was chosen ${ }^{24}$. The pressure was controlled by an automated back pressure regulator (Jasco BP 2080 Plus Automated BPR, Japan). The extraction of $\mathrm{SC}-\mathrm{CO}_{2}$ was started after achieving the required temperature and pressure. Within $80 \mathrm{~min}$ of the total extraction time, the extraction process was dynamically performed. Subsequently, the extract was placed in a centrifugal vacuum concentrator (Mivac Duo, UK) at $40{ }^{\circ} \mathrm{C}$ to evaporate the solvent. The extract was then placed in a freezer at $-20^{\circ} \mathrm{C}$ for further investigation. The extract yield of $H$. sabdariffa was determined as given in Equation 1.

$$
\text { Total yield }[\mathrm{mg} / \mathrm{g}]=(\operatorname{Mext}(\mathrm{mg})) /(\mathrm{F}[\mathrm{g}])
$$

where Mext is the total extracted mass and $\mathrm{F}$ is a feed mass on a dry basis.

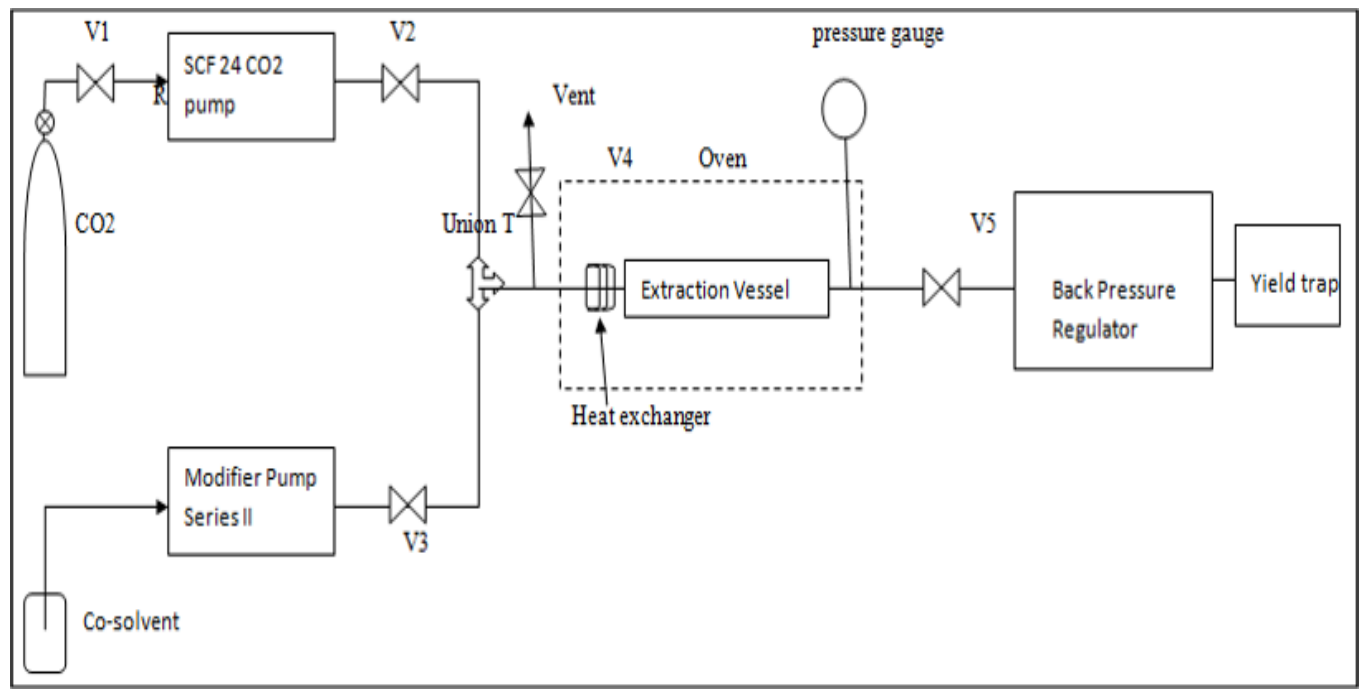

Figure 1. Schematic diagram of the $\mathrm{SC}-\mathrm{CO}_{2}$ experimental setup.

\section{Determination of anthocyanins content}

The quantification of monomeric anthocyanins (cyanidin 3-glucoside) was performed using Waters Breeze 2 High-Performance Liquid Chromatography (HPLC) equipped with 2475 multi $\lambda$ fluorescence detector, 717 plus autosampler, 1525 Binary HPLC pump, and temperature control module. For cyanidin 3-glucoside detection at $520 \mathrm{~nm}$, the $460 \mathrm{~mm} / 250 \mathrm{~mm} / 5 \mathrm{~mm}$ (MERCK, Darmstadt, Germany) RP C18 column was used with excitation and emission wavelength. Acetonitrile: water at a ratio of 65:35 was used as a mobile phase solvent and pumped at $1.0 \mathrm{~mL} / \mathrm{min} .30^{\circ} \mathrm{C}$ of column temperature was fixed with a sample volume of $20 \mu \mathrm{L}$ for injection. The compound was identified based on their retention time by comparing the sample's chromatography peak to the standard. The value of anthocyanin content was expressed in the mg cyanidin 3-glucoside/g sample.

\section{Semi-empirical modeling}

Calculation of solubility of total yield extract in $\mathrm{SC}-\mathrm{CO}_{2}$

Based on the calculation in Equation 2, the solubility $(S)$ of the extract is the difference between the mass of extracted yield $(\mathrm{g})$ and the variation of volume of carbon dioxide $(\mathrm{L})$ used ${ }^{25,26}$. The low percentage used for modifier was ignored in the solubility calculation in this section due to only minor changes in density at constant temperature and pressure. 


$$
S=\frac{\Delta \mathrm{y}[\mathrm{g}]}{\Delta \mathrm{x}[\mathrm{L}]}=\frac{y_{b}-y_{a}}{x_{b}-x_{a}}
$$

\section{Chrastil Model}

Based on the Chrastil model, temperature is the crucial parameter that affects the solubility of the solute. It was determined by taking the equilibrium of the solvent molecules into account. Equation 3 shows the solubility $(S)$ equation:

$$
S=\rho_{C O_{2}}^{k} \exp \left[\frac{a}{T}+b\right]
$$

The Chrastil model describes a relationship between the solute solubility, $\mathrm{S}(\mathrm{g} / \mathrm{L})$, and $\mathrm{SC}-\mathrm{CO}_{2}$ density $(\mathrm{g} / \mathrm{L})$. The value of $k$ defines the number of $\mathrm{SC}-\mathrm{CO}_{2}$ in solvated complex, $a$ is related to the extraction enthalpy (enthalpy of solvation and vaporization), $b$ depends on the molecular weight of the solute and solvent, and $\mathrm{T}$ is temperature conditions $(\mathrm{K})$.

Del Valle Aguilera (dVA) Model

Del Valle Aguilera ${ }^{21}$ further developed Chrastil's model. The addition of one adjustable parameter is related to temperature, thus maximizing the temperature dependency instead of density. The dVa equation is expressed as follows:

$$
S=\rho_{C O_{2}}^{k} \exp \left[\frac{a}{T}+\frac{b}{T^{2}}+c\right]
$$

The adjustable parameters are the value of $a$ and $b$, which correlates to the thermal effect. Meanwhile, the value of $c$ depends on the molecular weight of the solute and the solvent, and $\mathrm{T}$ is temperature conditions $(\mathrm{K})$.

\section{Adachi-Lu (A-L) Model}

Adachi Lu Model (A-L) is another variety of Chrastil models. This model assumed that the density of solvent has a significant impact on the solubility of extract. The association number (or coefficient), $k$, is thus modified to a quadratic polynomial. The A-L equation is shown in Equation 5.

$$
S=\left[k_{1}+c \rho_{\mathrm{CO}_{2}}+d \rho_{\mathrm{CO}_{2}}{ }^{2}\right] \ln \rho_{\mathrm{CO}_{2}}+\frac{a}{T}+b
$$

Coefficient values of $k_{1}, c$, and $d$ are the adjustable parameters to obtain the overall equilibrium constant and represent the average number of solvent molecules. $a$ is the adjustable parameter, which correlates to the thermal effect, while the value of $c$ depends on the molecular weight of the solute and the solvent. $\mathrm{T}$ remains as a temperature condition $(\mathrm{K})$.

\section{Statistical analysis}

For statistical analysis, the average absolute relative deviation percentage (AARD\%) was used in this study as it provides information on the error of agreement between the model and the experimental data. The equation for AARD\% is shown in Equation 6 below:

$$
\operatorname{AARD} \%=\frac{1}{n} \sum_{i=1}^{n}\left|\frac{\ln S_{\text {model }}-\ln S_{\text {exp }}}{\ln S_{\text {exp }}}\right|
$$

where $n$ is the number of data points, $S_{\text {exp }}$ is the experimental solubility data $(\mathrm{g} / \mathrm{L})$, and $S$ model is the solubility of model data $(\mathrm{g} / \mathrm{L})$.

\section{Results and discussion}

\section{$\mathrm{SC}-\mathrm{CO}_{2}$ experimental results}

Table 1 shows the experimental conditions used in this study and their effects on total yields, anthocyanins content, and extraction solubility of $H$. sabdariffa. The total yield ranged from $59.29 \mathrm{mg} / \mathrm{g}$ 
and $279.60 \mathrm{mg} / \mathrm{g}$. Meanwhile, the anthocyanin concentration range was relatively narrow, ranging from 10.12 to $12.41 \mathrm{mg} / \mathrm{g}$. $\mathrm{H}$. sabdariffa extract solubility was calculated to be between 0.41 and $3.29 \mathrm{~g}$ extract/L $\mathrm{CO}_{2}$.

Table 1. Experiment results (yield and anthocyanins) and solubility data were obtained from $\mathrm{SC}_{-} \mathrm{CO}_{2}$ operating conditions.

\begin{tabular}{|c|c|c|c|c|c|}
\hline $\begin{array}{l}\text { Pressure, } \\
\text { MPa }\end{array}$ & $\begin{array}{l}\text { Temperature, } \\
{ }^{\circ} \mathrm{C}\end{array}$ & Modifier Ratio [\%] & Total Yield [mg/g] & $\begin{array}{c}\text { Anthocyanins Content } \\
\text { [Cya-3-glu, mg/g] }\end{array}$ & $\begin{array}{c}\text { Solubility } \\
{\left[g_{\text {extract }} / L_{\mathrm{CO} 2}\right]}\end{array}$ \\
\hline \multirow{4}{*}{8} & & 5 & 88.73 & 10.28 & 0.52 \\
\hline & 50 & 7.5 & 179.03 & 10.96 & 0.82 \\
\hline & & 10 & 177.47 & 10.55 & 0.83 \\
\hline & & 5 & 119.95 & 12.41 & 0.89 \\
\hline \multirow[t]{2}{*}{8} & 60 & 7.5 & 240.90 & 10.58 & 2.02 \\
\hline & & 10 & 175.71 & 10.12 & 3.29 \\
\hline \multirow{3}{*}{8} & & 5 & 168.01 & 11.94 & 0.69 \\
\hline & 70 & 7.5 & 268.83 & 10.28 & 3.23 \\
\hline & & 10 & 225.50 & 10.15 & 0.91 \\
\hline \multirow{3}{*}{10} & & 5 & 123.06 & 10.49 & 0.59 \\
\hline & 50 & 7.5 & 171.13 & 11.19 & 1.29 \\
\hline & & 10 & 174.57 & 10.29 & 0.72 \\
\hline \multirow{3}{*}{10} & & 5 & 104.09 & 10.14 & 0.55 \\
\hline & 60 & 7.5 & 165.02 & 10.74 & 0.79 \\
\hline & & 10 & 215.28 & 10.71 & 1.45 \\
\hline \multirow{3}{*}{10} & & 5 & 144.53 & 10.41 & 1.12 \\
\hline & 70 & 7.5 & 243.85 & 10.62 & 0.99 \\
\hline & & 10 & 279.60 & 10.84 & 1.13 \\
\hline \multirow{3}{*}{12} & & 5 & 59.29 & 10.49 & 0.41 \\
\hline & 50 & 7.5 & 94.57 & 11.26 & 0.65 \\
\hline & & 10 & 103.44 & 11.70 & 0.52 \\
\hline \multirow{3}{*}{12} & & 5 & 85.58 & 10.15 & 0.67 \\
\hline & 60 & 7.5 & 120.42 & 11.14 & 0.80 \\
\hline & & 10 & 139.71 & 10.89 & 1.24 \\
\hline \multirow{3}{*}{12} & & 5 & 117.35 & 10.96 & 0.78 \\
\hline & 70 & 7.5 & 144.12 & 10.81 & 0.83 \\
\hline & & 10 & 214.39 & 12.28 & 1.83 \\
\hline
\end{tabular}

Effects of temperature, pressure, and modifier ratio on the extraction yield and anthocyanins content

Extraction yield is a solvent efficiency indicator for extracting different components from the original material. The yield was calculated by dividing the weight of the extract by the weight of the original sample. Meanwhile, anthocyanin content was calculated by dividing the amount of cyanidin 3-glucoside in the extract by the sample weight. We observed different trends in total yield and anthocyanins content based on pressure, temperature, and modifier ratio. The distinct trend of total yield and anthocyanins demonstrated the selectivity of the $\mathrm{SC}-\mathrm{CO}_{2}$ process.

Figure 3a indicates that the extraction yield increased as the temperature increased from $50^{\circ} \mathrm{C}$ to $70^{\circ} \mathrm{C}$ at constant pressures of $8 \mathrm{MPa}$ and $12 \mathrm{MPa}$, respectively. This pattern indicated that as the temperature increased, the total extract became more dependent on the pressure of the solute vapor, resulting in increased diffusivities of both the solvent and the solute ${ }^{27}$. The mobility of $\mathrm{CO}_{2}$ in the inner matrix was significantly influenced by the decrease in viscosity with increasing temperature. It will easily penetrate and reach the solid matrix's internal interior to recover a large amount of compound ${ }^{28}$. Besides, other compounds in $\mathrm{H}$. sabdariffa extract, such as phenolic acids (gallic acid, caffeic acid, ferulic acids), were more susceptible to temperature. Mohd Nasir ${ }^{29}$ reported that increasing the temperature from 50 to $70^{\circ} \mathrm{C}$ increased the total extraction yield of Quercus infectoria Galls. This pattern was due to the decrease of 
solvent density effect and an increase in solute volatility. Similarly, increasing the temperature reduced viscosity while increasing $\mathrm{CO}_{2}$ penetration into the Piper betel leaves, solute diffusion rate, and extraction yield ${ }^{30}$.

On the contrary, the anthocyanins content descended after the operating temperature increased from 50 to $70{ }^{\circ} \mathrm{C}$ (Figure 3b). A similar pattern was observed by Maran et al., ${ }^{31}$ and Ahmadian-Kouchaksaraie and Niazmand ${ }^{12}$, whereby the anthocyanins content started to drop as the temperature rose above 50 ${ }^{\circ} \mathrm{C}$. At high temperatures, one of the undesirable factors associated with the production of bioactive compounds was the thermal degradation of the solute. Therefore, the finding showed that anthocyanin degradation could have occurred at temperatures higher than $50{ }^{\circ} \mathrm{C}$.

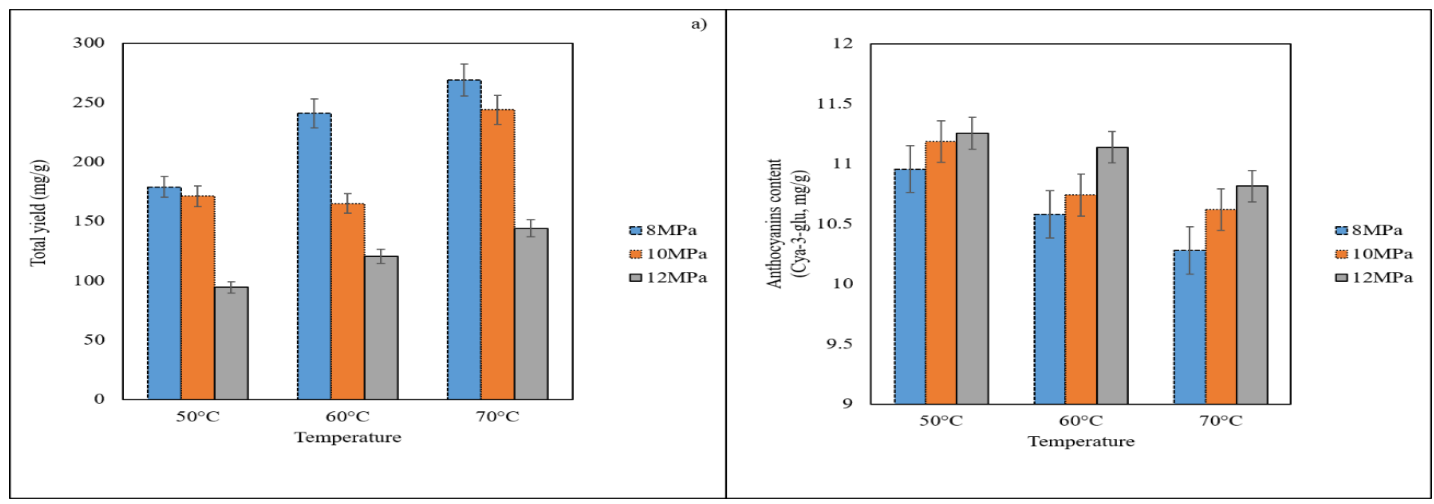

Figure 3. a) Total yield and b) Anthocyanins content (mg cyanidin 3-glucoside/g sample) at various temperatures with a $7.5 \%$ modifier ratio.

Meanwhile, when the effects of different pressures on total yield at different temperatures were investigated (Figure 4a), the extraction yield was significantly reduced from 8 to $12 \mathrm{MPa}$. The decrease in yield with increasing pressure could be attributed to the volatility and polarity of extracted solutes and the interaction of other parameters such as temperature. When the pressure was increased, the deformability of the $\mathrm{O}=\mathrm{C}=\mathrm{O}$ bond of $\mathrm{CO}_{2}$, polarity, density, and solubility of polar solutes increased simultaneously, leading to increased selectivity for specific polar content such as anthocyanins ${ }^{32}$, which may have resulted in the other compounds not being extracted.

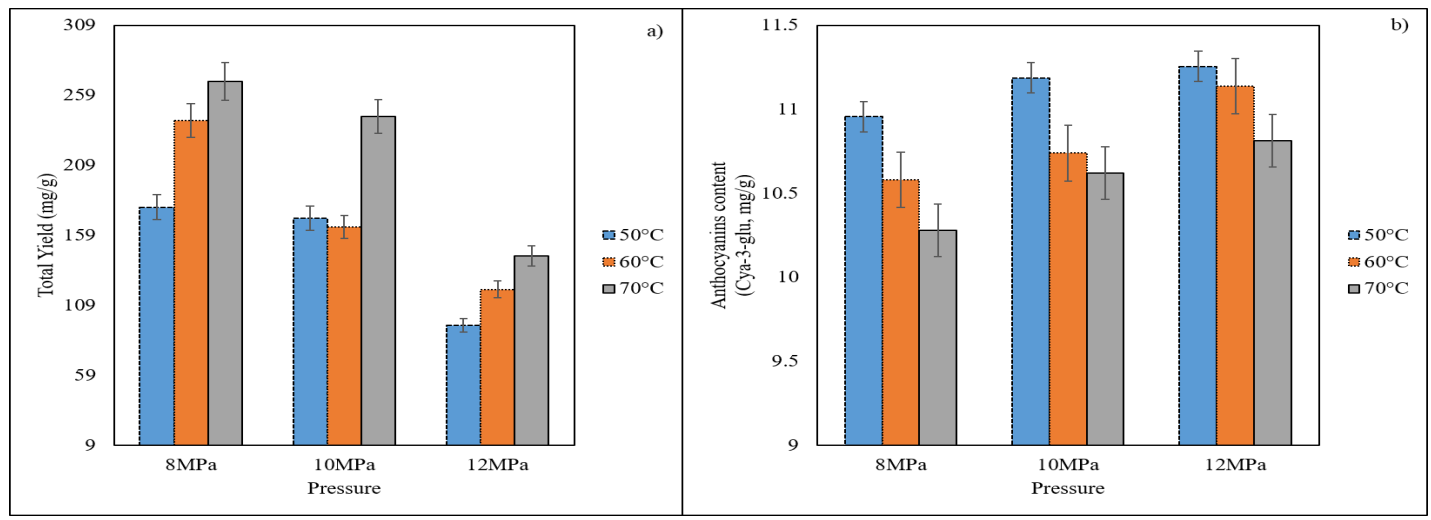

Figure 4. a) Total yield and b) Anthocyanins content (mg cyanidin 3-glucoside/g sample) at various pressures with $7.5 \%$ of a modifier ratio.

As shown in Figure 4b, the anthocyanin content rose at a constant temperature as the pressure rose from 8 to $12 \mathrm{MPa}$. The results were similar to those obtained by Ruan et al., ${ }^{33}$, who found that increasing the pressure improved the extract's polar compounds (i.e., quercetin and ginkgetin). Mandana et al., ${ }^{34}$ discovered similar results using 10 to $30 \mathrm{MPa}$ pressure when extracting bioactive compounds from 
spearmint (Menthaspicata L.). They observed that increasing the pressure from 10 to $20 \mathrm{MPa}$ increased the extraction yield due to increased $\mathrm{SC}-\mathrm{CO}_{2}$ density at higher pressures.

Figures $5 \mathrm{a}$ and $5 \mathrm{~b}$ show the effects of different modifier ratios on the total extraction yield and anthocyanins content at $10 \mathrm{MPa}$, respectively. Modifiers can improve the polarity of $\mathrm{SC}-\mathrm{CO}_{2}$ and facilitate the removal of solute from the plant matrix, thus improving yield and selectivity. By competing with solutes' active binding sites and altering their matrix structure, polar modifier molecules could speed up the dissociation process ${ }^{35}$. As the modifier percentage increased, the extraction yields increased. High modifier concentrations could also reduce the extract selectivity, depending on the size of phenolic ${ }^{36}$. At $70^{\circ} \mathrm{C}$, the same trend was observed with modifier ratios of 5 and $7.5 \%$. When temperatures in the $50-$ $60^{\circ} \mathrm{C}$ range were used, there was no significant increase in yield. Hence, a higher temperature $\left(70^{\circ} \mathrm{C}\right)$ with a higher modifier ratio $(10 \%)$ resulted in significant compound recovery due to improved mass transfer and less selectivity.

Conversely, as shown in Figure 5b, once the condition reached the maximum modifier usage, a larger volume of modifier (10\%) was insignificant at a constant temperature of 60 and $70{ }^{\circ} \mathrm{C}$ for anthocyanins content. Similar outcomes were observed in $\mathrm{SC}-\mathrm{CO}_{2}$ extraction of anthocyanins from Indian blackberry (jamun) ${ }^{31}$ and polyphenols from grape pomace ${ }^{37}$. Results showed that the target bioactive yield was stagnant when the modifier amount increased to a higher value. Manna et al., ${ }^{38}$ reported that this might be due to the modifier fractionation between the supercritical phase and the solid matrix exposed to SC$\mathrm{CO}_{2}$ could thermodynamically alter the system by ascending the affinity of the solute to the solid phase. It showed that at the end of the process, by adsorbing the ethanol molecules and remaining trapped in the solid matrix, some polyphenols were solubilized.

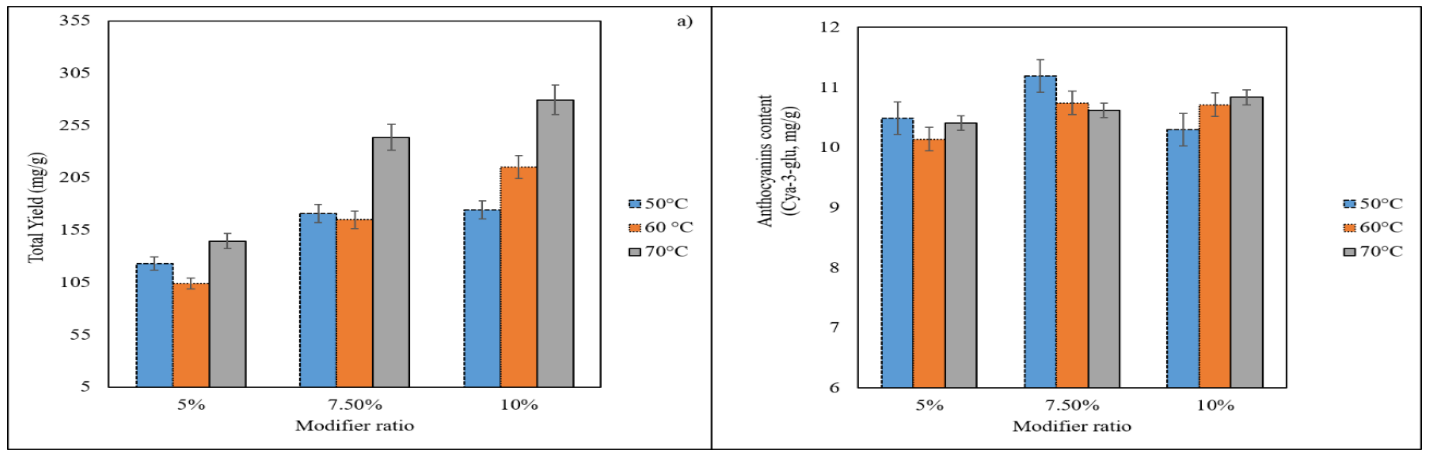

Figure 5. a) Total yield and b) Anthocyanin's content (mg cyanidin 3-glucoside/g sample) in three different modifier ratios $(5,7.5$, and $10 \%)$ under the constant pressure of $10 \mathrm{MPa}$.

\section{A Semi-empirical model for solubility of $H$. sabdariffa calyces extract}

Temperature and pressure are crucial factors influencing target compound solubility in supercritical fluid extraction, and they are strongly related to the solvating power of fluids in the supercritical phase. In this regard, pressure may influence $\mathrm{CO}_{2}$ density, whereas temperature may impact vapor pressure and diffusivity of target compounds.

The rise in pressure in this study did not improve the solubility due to a small range of pressure parameters (8 to $12 \mathrm{MPa}$ ), as shown in Table 1. Nevertheless, when using a wide range of pressure, the high pressure could significantly improve the solute solubility due to an increase in density ${ }^{25}$. Therefore, this finding contradicted the solubility of Quercus infectoria galls extracted when using the same extraction technique ${ }^{39}$. They reported that the solubility and solvation power increased when pressure increased to a certain level. Total phenolic and total flavonoid solubility of Arachis Hypogea also increased with the enhancement of pressure from 0.00108 to $0.042 \mathrm{mg} / \mathrm{Lmix}$ and 0.00056 to 0.00587 $\mathrm{mg} / \mathrm{Lmix}$, respectively ${ }^{25}$. Moreover, Camelia Sativa seed oil solubility also increased from $6.5 \times 10^{-3}$ to $1.33 \times 10^{-2}\left(\mathrm{~kg}_{\mathrm{oil}} / \mathrm{kg}_{\mathrm{co} 2}\right)$ when operating at a pressure between 35 to $45 \mathrm{MPa}{ }^{40}$. Therefore, to increase 
the solubility of the extracted solute, a wide range of pressure will be proposed in further research. Generally, to achieve solute high solubility, a high-temperature condition is preferred. The effect of vapor pressure in the extraction process is very dominant, resulting in higher solubility ${ }^{41}$. Table 1 shows a slight increase in solute solubility as the temperature rose at constant pressure. This result is similar to the peanut skin extract solubility, whereby increasing the temperature enhanced the solubility from 1.28 $x 10-3$ to $7.72 \times 10-3\left(g_{\text {extract }}\right) /\left(g_{\text {mix }}\right)^{42}$.

Table 2. Solubility fitting constant for three semi-empirical density-based correlations

\begin{tabular}{|c|c|c|c|c|c|c|c|c|c|c|}
\hline Model & $\begin{array}{c}{ }^{*} \mathrm{P} \\
{[\mathrm{MPa}]}\end{array}$ & $\begin{array}{l}* * \mathrm{~T} \\
{\left[{ }^{\circ} \mathrm{C}\right]}\end{array}$ & $\begin{array}{c}\text { Modifier ratio } \\
{[\%]}\end{array}$ & k & a & b & c & $d$ & $\% A A R D$ & $\begin{array}{c}{ }^{* * *} \mathrm{Av} \\
\% A A R D\end{array}$ \\
\hline \multirow{3}{*}{ Chrastil } & \multirow{9}{*}{$8-12$} & \multirow{9}{*}{$50-70$} & 5 & $1.24 \mathrm{E}-6$ & 108.15 & 0.37 & - & - & 23.57 & \\
\hline & & & 7.5 & 0.1 & 78.41 & 0.48 & - & - & 23.17 & 27.72 \\
\hline & & & 10 & $1.6 \mathrm{E}-6$ & 159 & 0.77 & - & - & 36.43 & \\
\hline \multirow{3}{*}{ dVA } & & & 5 & -0.05 & 329.54 & 0.38 & 0.012 & - & 24.24 & \\
\hline & & & 7.5 & 0.276 & 236 & 0.48 & 0.018 & - & 48.75 & 35.42 \\
\hline & & & 10 & -0.59 & 1595 & 0.76 & 0.011 & - & 33.28 & \\
\hline \multirow{3}{*}{$A-L$} & & & 5 & -0.018 & -21.48 & 0.81 & 0.003 & $-1.35 E-4$ & 77.50 & \\
\hline & & & 7.5 & 0.835 & -7413 & 1.32 & 0.017 & 0.185 & 40.49 & 50.22 \\
\hline & & & 10 & -0.649 & 1382 & 0.75 & 0.001 & $-2.4 \mathrm{E}-6$ & 32.68 & \\
\hline
\end{tabular}

${ }^{*} \mathrm{P}=$ Pressure,${ }^{* *} \mathrm{~T}=$ Temperature,${ }^{* * *} \mathrm{Av} \% \mathrm{AARD}=$ average percentage of AARD

Semi-empirical models, i.e., Chrastil, dVA, and A-L, were applied to determine the effect of studied parameters on $\mathrm{H}$. sabdariffa calyces extract solubility. The optimum fitting parameters for the correlation were obtained using the least AARD\% between model and experimental data. Table 2 shows the fitted parameters used for each relationship. The average AARD (\%) of Chrastil, dVA, and A-L models were $27.72 \%, 35.42 \%$, and $50.22 \%$, respectively. The Chrastil model correlated to the solute solubility with the lowest AARD (\%). The lowest percent of AARD showed that the Chrastil was the most successful model and associated with solute solubility compared to other semi-empirical models. Therefore, the coefficient value of the Chrastil model had accurately determined the parameters to enhance the solubility. As described in Equation 3, the coefficient value of a was related to temperature effects, whether the extraction reaction is exothermic or endothermic. $a=-\Delta H / R$, where $\Delta H$ is the sum of the solute's enthalpy of vaporization and solvation while $R$ is the gas constant ${ }^{43}$. Besides, the value of coefficient $b$ depends on the molecular weights of the solute and solvent ${ }^{44}$. The positive value of $k$ represents an increase in density, which increased $H$. sabdariffa calyces extract solubility.

Also, $k$ refers to the number of solvent molecules that bind with the solute ${ }^{22}$. In contrast, a negative value of $k$ indicated an increase in solvent density, thus reducing the extract solubility. Therefore, based on the coefficient value obtained, the extraction behavior could be distinguished to enhance the solubility process. In this analysis, a was positive, suggesting that the exothermic reaction was the most acceptable condition to increase the solubility ${ }^{45,46}$. Due to the negative value of $\Delta \mathrm{H}$, the heat process is unnecessary to enhance the reaction. Therefore, a further increase in temperature will not affect the solvation power of $\mathrm{CO}_{2}$ due to the decrease of the solvent density ${ }^{46,47}$ 


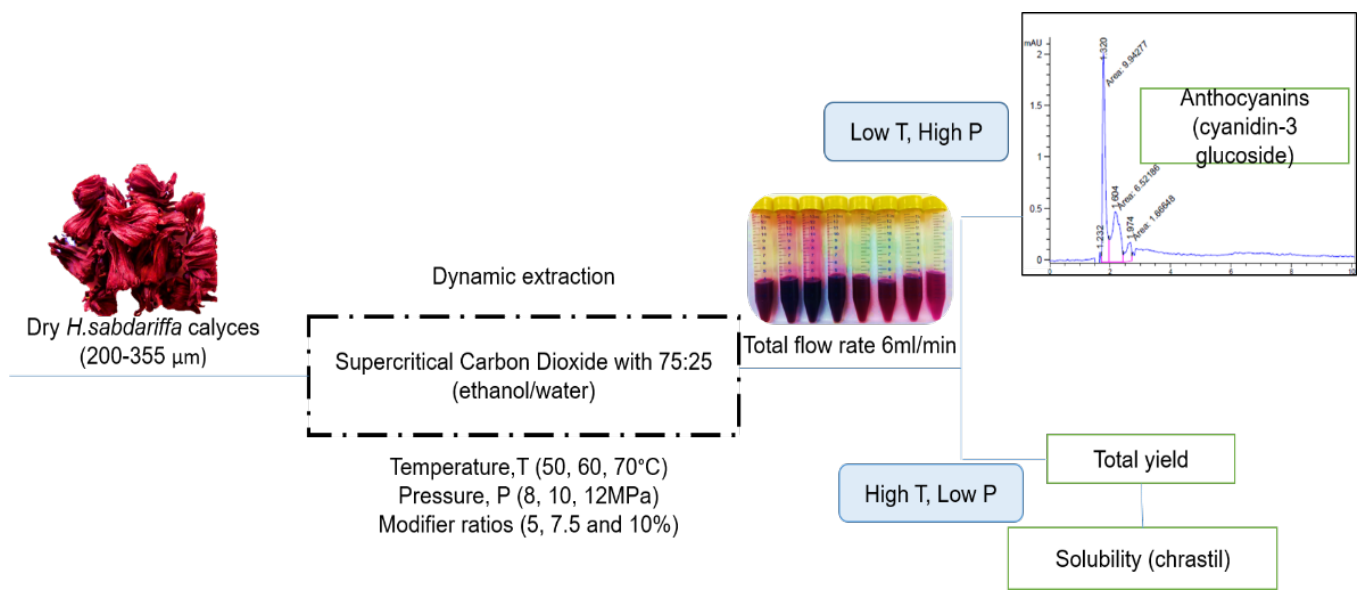

Figure 6. Summary of the main findings of the study.

\section{Conclusions}

In conclusion, this work observed the opposite trend of extraction yield and anthocyanins content from H.sabdariffa calyces extract within the selected ranges of $\mathrm{SC}-\mathrm{CO}_{2}$ condition. The modifier effect was insignificance on anthocyanins content at $10 \mathrm{MPa}$. The solubility of $H$.sabdariffa calyces extracts ranged from 0.41 to $3.29 \mathrm{~g} / \mathrm{L}$ in this study, and the Chrastil model was the most successful in correlating solute solubility when compared to the dVA and A-L models. The findings presented in this paper are the first steps toward developing more efficient extraction strategies and separation processes to obtain extracts with high anthocyanin concentrations from H.sabdariffa using $\mathrm{SC}_{-} \mathrm{CO}_{2}$ (Figure 6). Higher pressure ranges must be observed to evaluate the actual effects of $\mathrm{SC}-\mathrm{CO}_{2}$ chemical parameters such as temperature and pressure.

\section{Data availability}

The datasets generated during and/analyzed during the current study are available from the corresponding author on reasonable request.

\section{Conflicts of interest}

The author(s) declare(s) that there is no conflict of interest regarding the publication of this paper.

\section{Funding statement}

The authors are grateful to Universiti Teknologi Malaysia via UTMLead for the scholarship and the UTMPR RU grant (00L35) for the analysis and financial support.

\section{Acknowledgments}

The authors appreciate the Centre of Lipids Engineering and Applied Research (CLEAR), Universiti Teknologi Malaysia (UTM), for providing the $\mathrm{SC}-\mathrm{CO}_{2}$ and analysis equipment.

\section{References}

[1] Osman, M. et al. Morpho-agronomic analysis of three roselle (Hibiscus sabdariffa L.) mutants in tropical Malaysia. Aust. J. Crop Sci. 5, 1150-1156 (2011). 
[2] Aregbesola, O. A., Faborode, M. O. \& Hounkanrim, B. A. Studies on black tea production from fresh Roselle Calyxes. Int. Food Res. J. 25, 310-313 (2018).

[3] Obouayeba, A. P. et al. Phytochemical and antioxidant activity of roselle (Hibiscus Sabdariffa L.) petal extracts. Res. J. Pharm. Biol. Chem. Sci. 5, 1453-1465 (2014).

[4] Frimpong, G., Adotey, J., Ofori-kwakye, K., Kipo, S. L. \& Dwomo-fokuo, Y. Potential of aqueous extract of Hibiscus sabdariffa calyces as colouring agent in three paediatric oral pharmaceutical formulations. J. Appl. Pharm. Sci. 4, 1-7 (2014).

[5] Ngamwonglumlert, L., Devahastin, S. \& Chiewchan, N. Natural colorants: Pigment stability and extraction yield enhancement via utilization of appropriate pretreatment and extraction methods. Crit. Rev. Food Sci. Nutr. 57, 3243-3259 (2017).

[6] Pragalyaashree, M. M., Tiroutchelvame, D. \& Sashikumar, S. Degradation kinetics of anthocyanin extracted from roselle calyces (Hibiscus sabdariffa). J. Appl. Pharm. Sci. 8, 57-063 (2018).

[7] Miranda-Medina, A. et al. Optimization of Hibiscus sabdariffa L. (Roselle) anthocyanin aqueous-ethanol extraction parameters using response surface methodology. Sci. Study Res. Chem. Chem. Eng. Biotechnol. Food Ind. 19, 53-62 (2018).

[8] Cissé, M. et al. Aqueous extraction of anthocyanins from Hibiscus sabdariffa: Experimental kinetics and modeling. J. Food Eng. 109, 16-21 (2012).

[9] Garcia-Mendoza, M. del P. et al. Extraction of phenolic compounds and anthocyanins from juçara (Euterpe edulis Mart.) residues using pressurized liquids and supercritical fluids. J. Supercrit. Fluids 119, 9-16 (2017).

[10] Jiao, G. \& Kermanshahi pour, A. Extraction of anthocyanins from haskap berry pulp using supercritical carbon dioxide: Influence of cosolvent composition and pretreatment. LWT - Food Sci. Technol. 98, 237-244 (2018).

[11] Woźniak, Ł., Marszałek, K., Skąpska, S. \& Jędrzejczak, R. The application of supercritical carbon dioxide and ethanol for the extraction of phenolic compounds from Chokeberry pomace. Appl. Sci. 7, 1-12 (2017).

[12] Ahmadian-Kouchaksaraie, Z. \& Niazmand, R. Supercritical carbon dioxide extraction of antioxidants from Crocus sativus petals of saffron industry residues: Optimization using response surface methodology. $J$. Supercrit. Fluids 121, 19-31 (2017).

[13] Monroy, Y. M., Rodrigues, R. A. F., Sartoratto, A. \& Cabral, F. A. Influence of ethanol, water, and their mixtures as cosolvents of the supercritical carbon dioxide in the extraction of phenolics from purple corn cob (Zea mays L.). J. Supercrit. Fluids 118, 11-18 (2016).

[14] Mohamed-Mahmood, M., Daud, W. R. W., Markom, M. \& Mansor, C. N. A. N. C. Cosolvent selection for supercritical fluid extraction (SFE) of bioactive compounds from Orthosiphon stamineus. Sains Malaysiana 47, 1741-1747 (2018).

[15] Chuo, S. C. et al. A Glimpse into the Extraction Methods of Active Compounds from Plants. Crit. Rev. Anal. Chem. 0, 1-30 (2020).

[16] Pimentel-Moral, S. et al. Supercritical CO2 extraction of bioactive compounds from Hibiscus sabdariffa. J. Supercrit. Fluids 147, 213-221 (2019).

[17] Idham, Z. et al. Optimisation of supercritical CO2 extraction of red colour from roselle (Hibiscus Sabdariffa Linn.) calyces. Chem. Eng. Trans. 56, 871-876 (2017).

[18] Soetaredjo, F. E., Ismadji, S., Yuliana Liauw, M., Angkawijaya, A. E. \& Ju, Y.-H. Catechin sublimation pressure and solubility in supercritical carbon dioxide. Fluid Phase Equilib. 358, 220-225 (2013).

[19] Chrastil, J. Solubility of solids in supercritical gases. J. Chem. Phys. 77, 1512-1516 (1982).

[20] Adachi, Y. \& Lu, B. C.-Y. Supercritical fluid extraction with carbon dioxide and ethylene. Fluid Phase Equilib. $14,147-156$ (1983)

[21] Del Valle, J. M. \& Aguilera, J. M. An improved equation for predicting the solubility of vegetable oils in supercritical carbon dioxide. Ind. Eng. Chem. Res. 27, 1551-1553 (1988).

[22] Lukmanto, S. et al. Supercritical $\mathrm{CO} 2$ extraction of phenolic compounds in Roselle(Hibiscus Sabdariffa L.). Chem. Eng. Commun. 200, 1187-1196 (2013).

[23] Idham, Z. et al. Effect of flow rate, particle size and modifier ratio on the supercritical fluid extraction of anthocyanins from Hibiscus sabdariffa (L). IOP Conf. Ser. Mater. Sci. Eng. 932, (2020).

[24] Sapkele, G. N., Patil, S. M., Surwase, U. S. \& Bhatbhage, P. K. Supercritical Fluid Extraction. Int. J. Chem. Sci. 8, 729-743 (2010).

[25] Putra, N. R., Rizkiyah, D. N., Machmudah, S., Shalleh, L. M. \& Che Yunus, M. A. Recovery and solubility of flavonoid and phenolic contents from Arachis Hypogea in supercritical carbon dioxide assisted by ethanol as cosolvent. J. Food Process. Preserv. 1-9 (2020). doi:10.1111/jfpp.14768

[26] Abdul Aziz, A. H. et al. Solubility of sinensetin and isosinensetin from Cat's Whiskers (Orthosiphon stamineus) leaves in ethanol-assisted supercritical carbon dioxide extraction: experimental and modeling. Chem. Pap. 75, 6557-6563 (2021).

[27] Rahmawati, A. et al. Supercritical CO2 Extraction of Phytochemical Compounds from Mimosa pudica Linn. Chem. Eng. Commun. 202, 1011-1017 (2015).

[28] Tiono, R. D. et al. Investigation on supercritical $\mathrm{CO} 2$ extraction of black nightshade berries (Solanum nigrum linn.). Biointerface Res. Appl. Chem. 11, 13502-13515 (2021).

[29] Mohd-Nasir, H. et al. Optimization of the supercritical carbon dioxide extraction of Quercus infectoria galls 
extracts and its bioactivities. J. Food Process. Preserv. 45, 0-3 (2021).

[30] Aziz, A. H. A. et al. Optimization of supercritical carbon dioxide extraction of Piper Betel Linn leaves oil and total phenolic content. IOP Conf. Ser. Mater. Sci. Eng. 162, (2016).

[31] Maran, J. P. et al. Modeling and optimization of supercritical fluid extraction of anthocyanin and phenolic compounds from Syzygium cumini fruit pulp. J. Food Sci. Technol. 51, 1938-1946 (2014).

[32] Dai, W. et al. Influence of Modifier in Supercritical CO2 on Qualitative and Quantitative Extraction Results of Eucalyptus Ecential Oil. Am. J. Plant Sci. 09, 163-171 (2018).

[33] Ruan, X. et al. Optimization of Process Parameters of Extraction of Amentoflavone, Quercetin and Ginkgetin from Taxus chinensis Using Supercritical CO 2 Plus Co-Solvent. Molecules 19, 17682-17696 (2014).

[34] Mandana, B., Russly, A. R., Ali, G. \& Farah, S. T. Antioxidant activity of spearmint (Mentha spicata L.) leaves extracts by supercritical carbon dioxide (SC-CO2) extraction. Int. Food Res. J. 18, 543-547 (2011).

[35] Patil, A. A., Sachin, B. S., Wakte, P. S. \& Shinde, D. B. Optimization of supercritical fluid extraction and HPLC identification of wedelolactone from Wedelia calendulacea by orthogonal array design. J. Adv. Res. 5, 62935 (2014).

[36] Díaz-Reinoso, B., Moure, A., Domínguez, H. \& Parajó, J. C. Supercritical CO 2 Extraction and Purification of Compounds with Antioxidant Activity. J. Agric. Food Chem. 54, 2441-2469 (2006).

[37] Mantell, C., de la Ossa, E. \& Rodríguez, M. Supercritical Fluid Extraction of Anthocyanins from Grape Pomace. vol.2, pp. 615-1618 (2001).

[38] Manna, L., Bugnone, C. A. \& Banchero, M. Valorization of hazelnut, coffee and grape wastes through supercritical fluid extraction of triglycerides and polyphenols. J. Supercrit. Fluids 104, 204-211 (2015).

[39] Mohd Nasir, H., Md Salleh, L., Ismail, A. R. \& Machmudah, S. Solubility correlation of gall (Quercus infectoria) extract in supercritical $\mathrm{CO}_{2}$ using semi-empirical equations. Asia-Pacific J. Chem. Eng. 12, 790-797 (2017).

[40] Belayneh, H. D., Wehling, R. L., Reddy, A. K., Cahoon, E. B. \& Ciftci, O. N. Ethanol-Modified Supercritical Carbon Dioxide Extraction of the Bioactive Lipid Components of Camelina sativa Seed. J. Am. Oil Chem. Soc. 94, 855-865 (2017).

[41] Danlami, J. M., Zaini, M. A. A., Arsad, A. \& Yunus, M. A. C. Solubility assessment of castor (Ricinus communis $\mathrm{L})$ oil in supercritical $\mathrm{CO} 2$ at different temperatures and pressures under dynamic conditions. Ind. Crops Prod. 76, 34-40 (2015).

[42] Putra, N. R., Che Yunus, M. A. \& Machmudah, S. Solubility model of arachis hypogea skin oil by modified supercritical carbon dioxide. Sep. Sci. Technol. 54, 731-740 (2019).

[43] Marceneiro, S., Coimbra, P., Braga, M. E. M., Dias, A. M. A. \& De Sousa, H. C. Measurement and correlation of the solubility of juglone in supercritical carbon dioxide. Fluid Phase Equilib. 311, 1-8 (2011).

[44] Khimeche, K., Alessi, P., Kikic, I. \& Dahmani, A. Solubility of diamines in supercritical carbon dioxide: Experimental determination and correlation. J. Supercrit. Fluids 41, 10-19 (2007).

[45] Liu, T., Li, S., Zhou, R., Jia, D. \& Tian, S. Solubility of Triphenylmethyl Chloride and Triphenyltin Chloride in Supercritical Carbon Dioxide. J. Chem. Eng. Data 54, 1913-1915 (2009).

[46] Han, S., Wang, W., Jiao, Z. \& Wei, X. Solubility of Vitamin E Acetate in Supercritical Carbon Dioxide: Measurement and Correlation. J. Chem. Eng. Data 62, 3854-3860 (2017).

[47] Paula, J. T., Sousa, I. M. O., Foglio, M. A. \& Cabral, F. A. Solubility of protocatechuic acid, sinapic acid and chrysin in supercritical carbon dioxide. J. Supercrit. Fluids 112, 89-94 (2016). 